\title{
O LICENCIAMENTO AMBIENTAL DE SUINOCULTURAS NA REGIÃO DO ALTO SÃO FRANCISCO, MINAS GERAIS
}

\author{
Helena Botelho de Andrade ${ }^{1}$ \\ Luiz Otávio Moras Filho ${ }^{2}$ \\ Luís Antônio Coimbra Borges ${ }^{3}$
}

\section{RESUMO}

O Brasil é um dos principais países exportadores de carne suinícola, tendo produzido 3,643 milhões de toneladas em 2015. Porém, essa intensa produção animal ocasiona uma serie de impactos ambientais como a contaminação do solo e da água. Este trabalho teve como objetivo caracterizar o estado de adequação ambiental dos empreendimentos suinícolas licenciados no período de 2011 a 2015 na região do Alto São Francisco, Minas Gerais, observando principalmente as alternativas de mitigação de impactos utilizadas. A estatística utilizada foi a descritiva e a coleta de dados interpretativa, por meio de check-list. Verificou-se que o principal motivo de indeferimento de licenças foi a falta de cumprimento de condicionantes estabelecidas pelos órgãos ambientais. Os principais impactos ambientais negativos da suinocultura observados foram o grande volume de efluente gerado e da emissão de gases que contribuem com o aumento do efeito estufa. Entre as medidas mitigadoras, destaca-se o manejo do efluente por meio de biodigestores e queimadores, podendo ser reutilizado como insumo para fertirrigação ou geração de energia elétrica. A regularização ambiental é uma prática necessária para a sustentabilidade da atividade de suinocultura, proporcionando adequações necessárias à qualidade de vida.

Palavras-chave: dejetos de suínos, poluição das águas, poluição do solo, regularização ambiental.

\section{ENVIRONMENTAL LICENSING OF SWINE PRODUCTION IN IN ALTO SÃO FRANCISCO REGION, MINAS GERAIS STATE}

\begin{abstract}
Brazil is one of the main exporters of pork, with a production of 3.643 million tons in 2015. This intense animal production leads to a series of environmental impacts such as soil and water contamination. The objective of this study was to describe the environmental suitability status of licensed swine production from 2011 to 2015 in

\footnotetext{
${ }^{1}$ Graduada em Agronomia (UFLA). Mestre em Fitotecnia (UFLA). E-mail: helena.ba@outlook.com

${ }^{2}$ Graduado em Engenharia Florestal (UFLA). Mestre em Engenharia Florestal (UFLA). E-mail: lomf22@gmail.com

${ }^{3}$ Graduado em Engenharia Florestal (UFLA). Mestre em Engenharia Florestal (UFLA). Doutor em Engenharia Florestal (UFLA). Professor do Programa de Pós-Graduação em Engenharia Florestal (PPGEF), da Universidade Federal de Lavras (UFLA). E-mail: luis.borges@dcf.ufla.br
} 
Alto São Francisco region, Minas Gerais state, especially about the impact mitigation alternatives. The statistic used was descriptive and interpretive data collection through checklist method. It was found that the main reason for license refusal was the failure to follow the conditions established by environmental agencies. The main negative environmental impacts of swine production observed in the region are due to the large volume of swine slurry and the emission of greenhouse gasses. Among the mitigation measures, it is highlighted the management of swine slurry through biodigesters and burners, that can be reused as input for fertigation or even to generate electricity. Environmental regulation is a necessary practice for the sustainability of swine activity, providing necessary adjustments to the quality of life.

Keywords: environmental regulation, soil pollution, swine slurry, water pollution.

\section{INTRODUÇÃO}

A demanda de carne suína pelo mercado mundial tem sido crescente, por se tratar de uma fonte protéica de alta qualidade e de custo acessível. Após 1978, a carne suína consolidou-se como a mais importante fonte de proteína animal do mundo (CARVALHO, 2014), tendo o Brasil alcançado o quarto lugar no ranking de produção e exportação mundial (BRASIL, 2016).

$O$ estado de Minas Gerais destaca-se como o quarto maior estado em quantidade de animais abatidos, com uma população suína de 3.329 .671 de animais em 186.214 estabelecimentos de criação (IBGE, 2016). De acordo com Garcia e Aguiar (2011), as principais mesorregiões de criação de suínos são o Triângulo Mineiro/Alto Paranaíba (39\% das matrizes), Zona da Mata (25\%), Região Metropolitana de Belo Horizonte (12\%), Oeste de Minas (7\%) e Sul/Sudoeste de Minas (7\%).

Essa intensa produção animal ocasiona uma serie de impactos ambientais, em que se destacam, segundo a FAO (2005): a) a eutrofização de corpos d'água superficiais; b) a contaminação das águas subterrâneas por nitrato e patógenos; c) o excesso de nutrientes e metais pesados nos solos; d) a contaminação das águas e dos solos com patógenos; e) a liberação de amônia, metano e outros gases na atmosfera.

A produção de suínos se caracteriza como uma das atividades agropecuárias com maior impacto ambiental, devido a geração de efluentes em grande quantidade e com elevado teor de carga orgânica e minerais. Esses efluentes, ou dejetos, são constituídos por fezes, urina, água desperdiçada pelos bebedouros e de higienização, resíduos de ração e outros materiais decorrentes do processo criatório (KONZEN et al.,1998).

É comum a utilização de lâmina d'água nos criadouros para manter a temperatura agradável aos animais. A água funciona não só como regulador térmico dos animais nos galpões, mas como um veículo de transporte do efluente para o sistema de tratamento, o que por um lado é um benefício, por outro se cria um problema em razão do volume de efluente gerado.

A descarga do efluente da suinocultura nos cursos d'água contamina e eutrofiza esses ecossistemas. Mesmo quando o efluente se estabiliza, passando previamente por lagoas de decantação e estabilização, ao ser lançado em curso d'água ainda há a necessidade de análise do efluente, da classificação do curso d'agua e um estudo de autodepuração, para se ter certeza de que o mesmo conseguirá absorver a quantidade de efluente a ser descarregada. 
Alternativamente, em detrimento à descarga em curso d'água, o efluente da suinocultura estabilizado tem sido utilizado como fonte de matéria orgânica e nutrientes em áreas de pastagens ou de cultivo, com o uso da fertirrigação. Para esse procedimento, é necessário ter alguns cuidados e realizar a prática com um planejamento agronômico, visto que o efluente lançado em grande quantidade satura o solo, causa o acúmulo de metais pesados e, consequentemente, a lixiviação destes para corpos d'água superficiais e a contaminação de aquíferos subterrâneos.

De acordo com Oliveira et al. (2004), embora os dejetos de suínos apresentem baixas concentrações de zinco e cobre, minerais essenciais para a maioria dos seres vivos, sua aplicação em doses excessivas na fertirrigação pode resultar no acúmulo desses elementos no solo, intoxicando plantas e, consequentemente, animais até o topo da cadeia alimentar. Entre os principais metais pesados, o cobre e o zinco têm sido motivo de maior preocupação, uma vez que são importantes componentes do suplemento dietético de rações e de formulação de antibióticos, o que aumenta os riscos de contaminação ambiental.

$\mathrm{O}$ efluente aplicado com orientação técnica torna-se um benefício para as áreas agricultáveis. Segundo a Secretaria de Estado de Meio Ambiente e Desenvolvimento Sustentável (SEMAD, 2016), "o esterco suíno é capaz de substituir, em alguns casos, a adubação química das culturas, pois, além de fornecer nutrientes às plantas, promove melhoria nas propriedades químicas, físicas e biológicas do solo". A suinocultura pode se tornar uma atividade em ciclo, transformando o efluente e os resíduos gerados em insumos.

Outro impacto gerado pelo efluente suinícola é a alta emissão de gases, especialmente o metano, que contribui expressivamente para o aumento do efeito estufa. Para mitigar esse impacto podem ser utilizados biodigestores anaeróbios, que são câmaras fechadas, onde dejetos de animais são introduzidos e fermentados anaerobicamente por bactérias (GASPAR, 2003). O biodigestor anaeróbio se tornou o primeiro projeto de modelo sustentável, referente ao Mecanismo de Desenvolvimento Limpo (MDL) implantado no Estado de Minas Gerias (KONZEN, 2005). Esse mecanismo, previsto no Protocolo de Quioto, admite que países em desenvolvimento certifiquem projetos de redução de emissão de gases de efeito estufa e vendam essas reduções certificadas para países desenvolvidos, auxiliando o cumprimento de suas metas (FEAM, 2011).

O cuidado com o meio ambiente pode se tornar um investimento econômico, visto que as práticas ambientais também podem causar a diminuição de custos para o produto, uma vez que minimiza o tratamento de resíduos, reduz o consumo de matéria-prima e evitam-se gastos com multas (HERNANDES et al., 2010). Além disso, para uma maior inserção no comércio internacional de carnes suína, faz-se necessário adequar os seus sistemas produtivos às exigências ambientais de seus principais mercados compradores (MIRANDA, 2005).

Em Minas Gerais, o pilar da regularização ambiental está na Deliberação Normativa (DN) no 74/2004 do Conselho de Política e Meio Ambiente (COPAM), que estabelece as atividades passíveis de regularização ambiental no estado.

A DN-74/2004 é uma norma aprovada pelo Conselho Estadual de Política Ambiental (COPAM), vigente em todo o Estado, que estabelece critérios para a classificação de empreendimentos e atividades modificadoras no meio ambiente, segundo o porte e potencial poluidor. Também determina as regras para a indenização dos custos de análise dos pedidos de licenciamento, a Autorização Ambiental de Funcionamento (AAF) (SEMAD, 2016). 
De acordo com o porte e o potencial poluidor da atividade realizada pelo empreendimento, que pode ser pequeno $(P)$, médio $(M)$ ou grande $(G)$, haverá a sua classificação entre as classes de 1 a 6 , conforme o quadro 1.

Quadro 1- Determinação da classe do empreendimento a partir do potencial poluidor da atividade e do porte.

\begin{tabular}{|c|c|c|c|c|}
\cline { 3 - 4 } \multicolumn{2}{c|}{} & \multicolumn{3}{c|}{$\begin{array}{c}\text { Potencial poluidor/degradador } \\
\text { geral da atividade }\end{array}$} \\
\cline { 3 - 5 } \multicolumn{2}{c|}{} & $\mathrm{P}$ & $\mathrm{M}$ & $\mathrm{G}$ \\
\hline $\begin{array}{c}\text { Porte do } \\
\text { Empreendimento }\end{array}$ & $\mathrm{P}$ & 1 & 1 & 3 \\
\cline { 2 - 5 } & $\mathrm{M}$ & 2 & 3 & 5 \\
\cline { 2 - 5 } & $\mathrm{G}$ & 4 & 5 & 6 \\
\hline
\end{tabular}

Fonte: Minas Gerais (2004).

Os empreendimentos cujas atividades são classificadas como Classe 1 e 2, de acordo com seu porte e potencial poluidor, são objetos de Autorização Ambiental de Funcionamento (AAF), que é um processo de regularização ambiental simplificado. Já, os empreendimentos cujas atividades se enquadram nas classes 3 a 6 são objetos de licenciamento ambiental. A suinocultura, de acordo com essa DN 74/2004, possui potencial poluidor médio. Quanto ao porte, se o empreendimento se enquadra como pequeno, este é passível de Autorização Ambiental de Funcionamento (AAF) e, se enquadrar em médio ou grande porte, o empreendimento deverá formalizar processo de licenciamento ambiental.

O processo de licenciamento ambiental clássico (ou preventivo) se constitui pelas fases de Licença Prévia (LP), Licença de Instalação (LI) e Licença de Operação (LO). No entanto, buscando a regularidade ambiental de atividades iniciadas à revelia do controle público, admite-se no estado de Minas Gerais o licenciamento ambiental de caráter corretivo, seja por meio da Licença de Instalação Corretiva (LIC), direcionada para empreendimentos instalados ou em instalação, ou pela Licença de Operação Corretiva (LOC), direcionada para empreendimentos em operação e que, em ambos os casos, ainda não procederam ao licenciamento ambiental. Nesses casos, para a continuidade da instalação ou do funcionamento do empreendimento, sem o devido embargo, concomitantemente ao trâmite do processo de licenciamento ambiental deverá ser obtida assinatura de Termo de Ajustamento de Conduta (TAC) com o Órgão Ambiental com condições e prazos para a instalação ou funcionamento até a sua regularização (MINAS GERAIS, 2008).

Este trabalho teve como objetivo caracterizar o estado de adequação ambiental dos empreendimentos suinícolas licenciados no período de 2011 a 2015 na região do Alto São Francisco, Minas Gerais, observando principalmente as alternativas de mitigação de impactos utilizadas.

\section{MATERIAL E MÉTODOS}

A coleta de dados foi realizada junto ao órgão responsável pelo licenciamento ambiental no estado de Minas Gerais, a Superintendência Regional de Regularização Ambiental (SUPRAM), na regional do Alto São Francisco (ASF). A regional SUPRAM - ASF contempla 66 municípios, tendo sua sede em Divinópolis e conta com o apoio de quatro Núcleos Regionais de Regularização Ambiental nos municípios de Arcos, Pará de Minas, Oliveira e Pompéu (figura 1). 
Figura 1 -Mapa de localização da área de estudo: Superintendência Regional de Regularização Ambiental (SUPRAM), regional do Alto São Francisco (ASF). Destaque para o município sede (Divinópolis) e para Núcleos Regionais de Regularização Ambiental (Arcos, Pará de Minas, Oliveira e Pompéu).

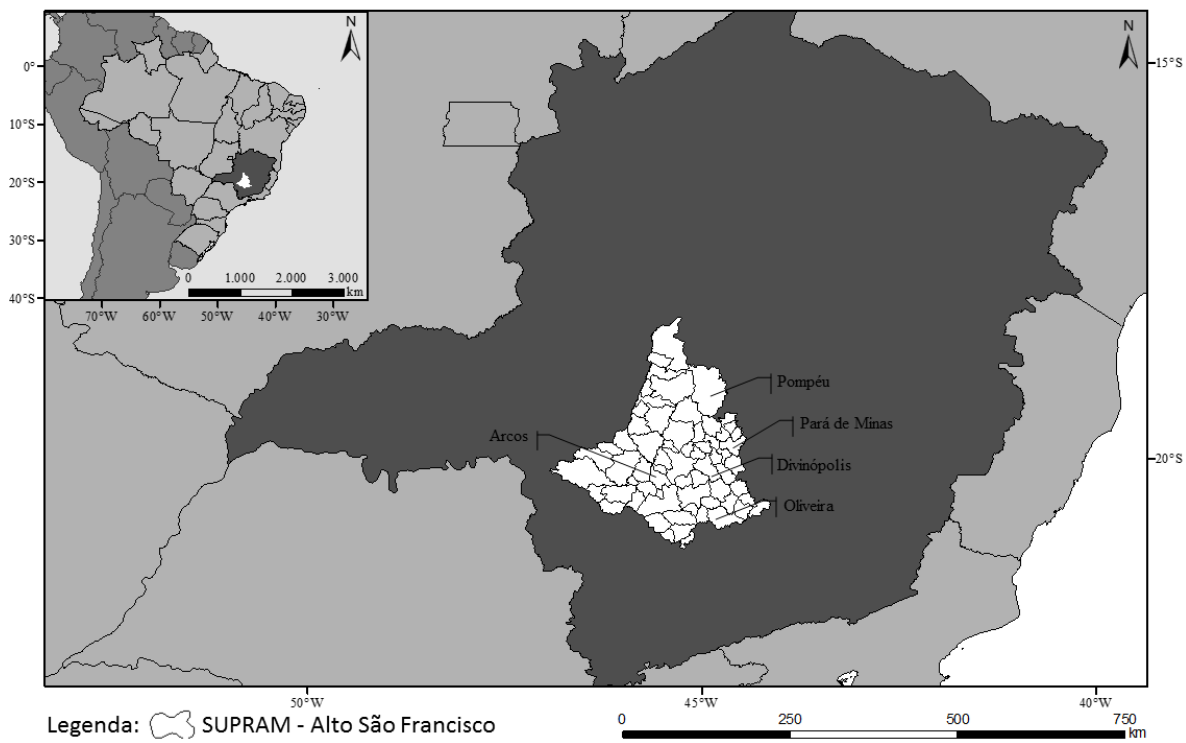

Fonte: elaborado pelos autores.

Foram analisados todos os processos de licenciamento ambiental entre os anos de 2011 a 2015 dos empreendimentos suinícolas na região de estudo. Primeiramente, foram separados os empreendimentos de classe 1 e 2, cujo licenciamento ambiental ocorre mediante Autorização Ambiental de Funcionamento (AAF). Posteriormente, foram analisados os empreendimentos de classe 3 a 6 julgados no Conselho Estadual de Política Ambiental (COPAM). Os empreendimentos foram classificados de acordo com as seguintes atividades: "Suinocultura Ciclo Completo", "Suinocultura Crescimento e Terminação" e "Suinocultura Unidade de Produção de Leitões", conforme DN n 74/2004 do COPAM. A estatística utilizada foi a estatística descritiva, e os dados foram analisados de forma interpretativa.

Inicialmente foi feito um check-list para coleta de dados dos processos de licenciamento ambiental (quadro 2). Ainda, foram anotadas observações de cada processo visando a buscar os gargalos dos aspectos ambientais da atividade de suinocultura, bem como as dificuldades e melhorias enfrentadas nessas atividades. 
Quadro 2- Check-list aplicado aos processos de licenciamento ambiental da região do Alto São Francisco, referente às atividades de suinocultura licenciadas entre 2011 e 2015.

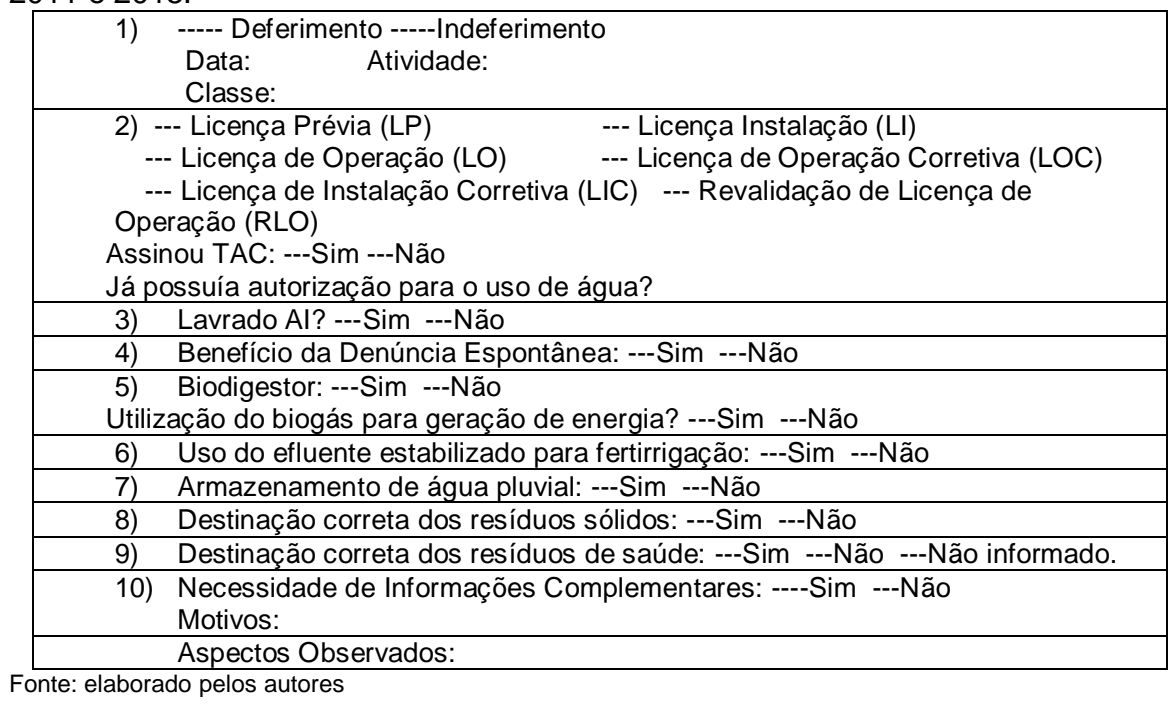

\section{RESULTADOS E DISCUSSÃO}

A maioria dos empreendimentos suinícolas licenciados entre os anos de 2011 e 2015 na região do Alto São Francisco foi enquadrada nas classes 1 ou 2, ou seja, sua regularização seguiu o padrão simplificado, por meio de Autorização Ambiental de Funcionamento (AAF). Nesse período, foram emitidas $112 \mathrm{AAF}$ na região, sendo uma média de 22 autorizações por ano.

A AAF se caracteriza como uma forma de regularização ambiental menos burocrática e mais ágil para empreendimento de classe 1 ou 2. Porém, para esse tipo de regularização não são realizadas vistorias prévias e as informações do processo são declaratórias, de responsabilidade do empreendedor e do responsável técnico das atividades do empreendimento. A fiscalização dos empreendimentos geralmente é feita por amostragem, devido ao número restrito de funcionários em relação à quantidade de processos. Viana e Bursztyn (2010) afirmam que, apesar de agilizar a regularização dos empreendimentos, a AAF exclui a elaboração de estudo de impacto ambiental, correndo 0 risco do órgão ambiental autorizar empreendimentos em locais e condições inadequadas.

Carvalho (2014), estudando a regularização da atividade de suinocultura na bacia hidrográfica do Rio Piranga, envolvendo 77 municípios, detectou que dos 114 empreendimentos suinícolas, 56 foram regularizados por meio de AFF e 58 pelo licenciamento ambiental convencional. Esse autor também verificou que apenas 74 empreendimentos estão em conformidade com a legislação aplicável, sendo que 29 foram licenciados por meio de LO, 34 por AAF e11 foram dispensados de licença.

No presente estudo, em relação aos empreendimentos suinícolas de classe 1 a 6 , identificou-se que 12 empreendimentos tiveram sua licença deferida e 2 tiveram licença indeferida entre 2011 e 2015. Além disso, foi identificado qual o tipo de licença foi concedida a cada empreendimento, conforme figura 2. 
Figura 2 -Número de empreendimentos suinícolas na região do Alto São Francisco: (a) que tiveram licença ambiental deferida ou indeferida entre 2011 e 2015; (b) por classe, segundo DN 74/2004 do COPAM, licenciados por meio de: Licença Prévia e Licença de Instalação (LP + LI); Licença de Operação (LO); Licença de Operação Corretiva (LOC); Revalidação da Licença de Operação (RLO).

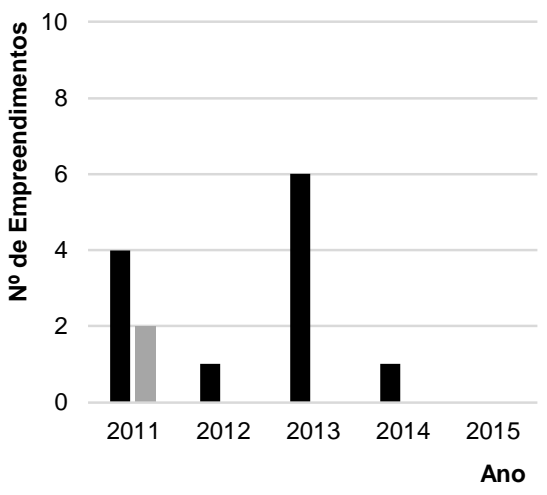

(a)
- Deferimento Indeferimento

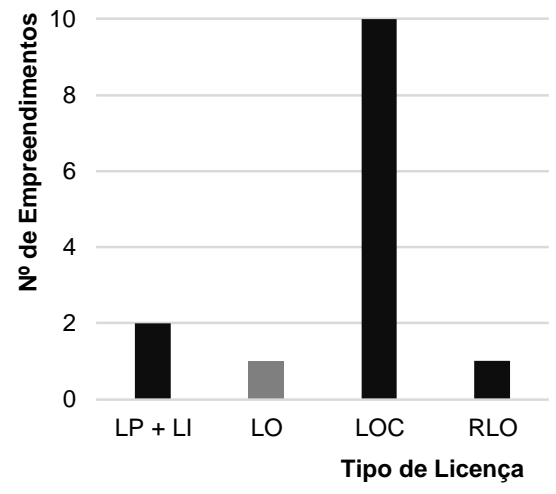

(b)

- Classe 3 Classe 4

Fonte: elaborado pelos autores

$\mathrm{Na}$ região de estudo houve um predomínio da tipologia de LOC, entre as quais, existem empreendimentos que estão se regularizando pela primeira vez, sendo que alguns fazem jus ao benefício da autodenúncia ou denúncia espontânea. Tipificada pelo artigo 15 do Decreto Estadual no 44.844/2008 (que estabelece normas para licenciamento ambiental e AAF, tipifica e classifica infrações às normas de proteção ao meio ambiente e aos recursos hídricos e estabelece procedimentos administrativos de fiscalização e aplicação das penalidades), a denúncia espontânea é um benefício para os empreendimentos que operavam sem licença anteriormente a publicação desse decreto, em que será excluída a aplicação da penalidade mediante formalização de pedido de licenciamento em caráter corretivo (MINAS GERAIS, 2008).

Ainda, houveram empreendimentos que já possuíram Licença de Operação e requereram a Revalidação da Licença de Operação (RLO), a qual foi indeferida antes de entrarem com o processo de LOC, devido ao não cumprimento de condicionantes impostas no licenciamento, o que acarretou em desempenho ambiental insatisfatório do empreendimento.

Entre os 10 processos de LOC, somente em um "parecer único de licenciamento" foi informada a suspensão das atividades e a assinatura de Termo de Ajustamento de Conduta. Como se trata de uma atividade que utiliza carga animal viva, não é possível, simplesmente embargar seu funcionamento. Para se aplicar o Decreto no 44.844/2008 necessita-se de um cronograma de desativação de suas atividades para que possam ser de fato desativadas.

Em relação ao uso do recurso hídrico, ressalta-se que, segundo Portaria $n^{\circ}$ 49/2010 do Instituto Mineiro de Gestão das Águas (IGAM), todas as outorgas de direito de uso de recursos hídricos deverão estar vinculadas ao processo de regularização ambiental. Dos 10 empreendimentos licenciados corretivamente na 
região de estudo, 3 tiveram que regularizar o uso da água como condicionante para obtenção da LOC.

Os autos de infração citados nos pareceres únicos (aqueles que subsidiam o julgamento da licença pelo COPAM) dos empreendimentos licenciados corretivamente foram lavrados, principalmente, em consequência do empreendimento operar sem licença ambiental (30\%), operar com parâmetro superior ao que foi autorizado $(30 \%)$ ou por ter suprimido vegetação nativa sem autorização (10\%).

Entre os empreendimentos analisados, os ajustes técnicos solicitados via oficio de informação complementar, ordenados de acordo com a frequência, foram:

- implantação de sistema de tratamento aos efluentes sanitários, ou o direcionamento destes para a Estação de Tratamento de Efluentes Industriais (ETEI), como biodigestores e /ou lagoas de decantação e estabilização;

- construção de composteira ou adequação da composteira existente no empreendimento;

- solicitação de comprovação da destinação adequada de resíduos sólidos, inclusive os de saúde, como pipetas, frascos de medicamentos e materiais para inseminação;

- solicitação da apresentação de planejamento do manejo agronômico da fertirrigação;

- solicitação de Plano de Recuperação de Áreas Degradadas (PRAD) nos casos em que a ETEI seria desativada por não se mostrar eficiente, ou nos casos da desativação devido ao piezômetro próximo à lagoa apresentar analises de contaminação do lençol freático;

- apresentação de PRAD em decorrência dos processos erosivos no solo;

- implantação de caixa separadora de água e óleo em posto de abastecimento e/ou lavador de veículos dentro da propriedade; e

- regularização do lançamento do efluente estabilizado no curso d'água e a apresentação de um estudo de autodepuração do curso d'água.

Em se tratando do lançamento de efluente em curso d'água, ressalta-se que a outorga para lançamento em curso d'água ainda não foi implementada pelas SUPRAMs.

Em estudos do impacto ambiental de suinoculturas no Vale do Taquari (Rio Grande do Sul), Hernandes et al. (2010) observaram que, em relação às melhorias a serem realizadas para a concessão de licença ambiental, o item mais crítico foi o tratamento dos dejetos. Também foi indicada por esse autor a necessidade de melhor manejo dos animais mortos, pela implantação ou melhoria do sistema de compostagem, além da necessidade de melhorar as instalações das granjas para melhor alocação dos animais.

Em relação aos efluentes da suinocultura, no Brasil é muito comum o uso de lagoas de decantação e estabilização. Porém é necessária a adequação desses ambientes, visto que, segundo Carvalho (2014), a ausência de revestimento impermeabilizante, na maioria delas, ocasionou uma pluma de contaminação que leva à sobrecarga da capacidade de filtração do solo e retenção dos elementos químicos, que podem percolar e contaminar o lençol freático.

Quanto ao uso de biodigestores anaeróbicos, 63\% dos empreendimentos analisados no presente estudo possuem esse equipamento, além das lagoas de decantação e estabilização no seu sistema de tratamento dos efluentes da suinocultura. Os demais contam somente com as lagoas. Somente dois empreendimentos $(28,5 \%)$ daqueles que possuem biodigestores, utilizam o biogás 
como energia para aquecimento. Os demais empreendimentos apenas queimam o biogás antes do seu lançamento na atmosfera.

Assim como observado no presente estudo, Carvalho (2014) identificou que na bacia hidrográfica do rio Piranga a tecnologia do biodigestor e as lagoas de estabilização estão respectivamente entre as tecnologias mais usadas na região. A forma de disposição do efluente são de $46,81 \%$ dos empreendimentos com biodigestor, 38,30 \% com lagoas e 14,89\% sem informação. No entanto, para essa região, a principal disposição final do efluente é o lançamento no curso d'água, sendo que 53,19 \% destinam em curso d'água, 31,91\% fertirrigação e 14,8\% sem informação. Conforme esse mesmo autor, a gestão do licenciamento ambiental deve ser aprimorada quanto à certeza de viabilidade técnica para o lançamento de efluente, sendo compatível com a capacidade de recebê-lo no curso d'água.

Nascimento e Rodrigues (2012) verificaram que o biodigestor anaeróbio pode reduzir a carga orgânica em até $84 \%$ e a Demanda Bioquímica de Oxigênio (DBO) em $78 \%$. Com a adição de agentes de biorremediação é possível chegar a uma redução de $96 \%$ de DBO e de Demanda Química de Oxigênio (DQO). Os mesmos autores descrevem que o biodigestor ajuda na redução do mau cheiro provocado pelos dejetos, na eliminação do uso de agentes químicos (agrotóxicos) no cultivo agrícola e eliminação de moscas e pragas nos cultivos, tornando-se um equipamento minimizador dos impactos negativos no meio ambiente.

O uso de biodigestores anaeróbicos na suinocultura é uma tecnologia para mitigação de impactos que contribuem para o aumento do efeito estufa. Essa técnica apresenta ganhos de créditos das Reduções Certificadas de Emissões (RCEs) para o financiamento de créditos de carbono, por possibilitar a produção de energia e por permitir a obtenção de insumos orgânicos ou biofertilizantes (NASCIMENTO; RODRIGUES, 2012).

Todos os empreendimentos da região de estudo realizam a fertirrigação do solo em áreas da propriedade com o efluente da suinocultura estabilizado. Somente um empreendimento, além da fertirrigação, também lançava o efluente em corpo hídrico. Essa prática, se utilizada de maneira correta, pode contribuir para melhorar a fertilidade do solo, porém, se aplicada sem um plano agronômico, pode causar danos como a saturação do solo e a contaminação do lençol freático e das águas subterrâneas.

O uso do efluente estabilizado na fertirrigação evita seu lançamento direto em cursos d'agua, contribuindo na minimização dos custos com análises de autodepuração do curso d'água e dos monitoramentos. O aproveitamento de águas residuárias na fertirrigação possibilita o aumento de produtividade e qualidade dos produtos colhidos, redução da poluição ambiental, melhoria nas características químicas, físicas e biológicas do solo, redução dos custos de produção (SOUZA et al., 2010), além de redução do consumo de água. O custo com adubos que podem ser reduzidos, por exemplo, corresponde a cerca de $20 \%$ dos custos totais de um cultivo (INSTITUTO FNP, 2009).

Mera et al. (2011), em estudo desenvolvido município de Tapera (RS), identificaram que a utilização dos dejetos da suinocultura como fertilizantes em lavoura agregou valor a um efluente antes sem destino e diminuiu custos com fertilizantes químicos.

Oliveira et al. (2004), em experimento com águas residuais da suinocultura em plantio de milho, observou que os valores de $\mathrm{pH}$ permaneceram praticamente inalterados, apresentando acidez classificada como média. Os níveis de fósforo, potássio, sódio, cálcio, magnésio, cobre e zinco no solo aumentaram, a acidez trocável do solo (Al3+) decresceu, provavelmente em razão do maior valor de $\mathrm{pH}$ dessas águas residuárias em relação à água da represa, sendo que o nível de $\mathrm{Fe}$ 
praticamente não foi alterado. O autor, ainda destacou que apesar da tendência de aumento da Produção de Matéria Seca (PMS) e de nutrientes, deve-se considerar a possibilidade de ocorrência de contaminação de águas subterrâneas e de salinização do solo.

Souza (2010), em estudo sobre a aplicação do efluente primário de água residuária da suinocultura em frutos de tomate de mesa, concluiu que a aplicação de Água Residuária da Suinocultura Filtrada (ARSF) não alterou as características de qualidade dos frutos do tomateiro com relação aos valores recomendados e, para quaisquer lâminas, a aplicação de ARSF resultou em frutos saborosos e saudáveis do ponto de vista sanitário. Esse autor também observou que a contagem de coliformes totais foi influenciada pela proximidade dos frutos em relação ao reservatório de ARSF e não pelas lâminas aplicadas.

A captação de águas pluviais também pode contribuir na sustentabilidade da atividade, visto que muitos suinocultores utilizam o manejo de criação com lamina d'agua nos galpões. Isso implicaria na redução de captação de água subterrânea ou superficial existente na propriedade, além de ser um aspecto positivo a ser avaliado em processos de revalidação de licença. No entanto, nenhum parecer único fez referência a essa prática na região de estudo.

Outro aspecto importante avaliado durante a concessão de licença ambiental é a destinação dos resíduos sólidos. Na região, verificou-se que os resíduos dos empreendimentos suinícolas não tinham sua destinação adequada, principalmente os resíduos de saúde. No licenciamento ambiental, os empreendimentos são obrigados a comprovar a destinação correta dos resíduos sólidos por meio de notas fiscais e da licença ambiental das empresas destinatárias. Além disso, é comumente solicitado como condicionante para obtenção de licença, o armazenamento temporário de resíduos sólidos no empreendimento, de acordo com as seguintes normas da Associação Brasileira de Normas Técnicas (ABNT): NBR $10.004,11.174$ e 12.235. Também se solicita um relatório da disposição e destinação desses resíduos periodicamente.

Todos os processos analisados necessitaram de pedido de informações complementares, seja para adequações técnicas ou jurídicas, ou para complementar o estudo apresentado de forma insuficiente. Os principais motivos foram:

- necessidade de adequações técnicas;

- ausência de documentos no processo, como a Assinatura de Responsabilidade Técnica (ART), notas fiscais da comprovação da destinação dos resíduos sólidos, averbação ou compensação da Reserva Legal, comprovação que a intervenção em Área de Preservação Permanente (APP) configura uso antrópico consolidado, regularização de uso da agua, regularização de intervenção em APP, regularização de supressão por meio de Autorização para Exploração Florestal (APEF) e Auto de Vistoria do Corpo de Bombeiros (AVCB), no caso do empreendimento possuir armazenamento de óleo diesel; e

- necessidade de complementação dos estudos ambientais no processo quando estão deficientes.

O descumprimento das informações complementares solicitadas pelo órgão ambiental é motivo de arquivamento do processo, devendo o empreendedor formalizar novo processo para se regulamentar e pagar novos custos de licenciamento. Assim, para nova regularização ambiental dos processos indeferidos torna-se necessária uma nova formalização de licenciamento, agora de forma corretiva. 


\section{CONSIDERAÇÕES FINAIS}

Dos 126 empreendimentos suinícolas licenciados na região do Alto São Francisco, no período de 2011 a 2015, 112 (88,9\%) foram regularizados por meio de Autorização Ambiental de Funcionamento, por se enquadrarem em classe 1 ou 2 em função do potencial poluidor da atividade e do porte do empreendimento. Entre os demais (classes 4 a 6), 10 empreendimentos (7,9\%) foram licenciados em caráter corretivo e apenas $4(3,2 \%)$ em caráter preventivo (abrangendo as Licenças Prévia, de Instalação e de Operação, bem como a Revalidação da Licença de Operação).

A Autorização Ambiental de Funcionamento possui caráter declaratório, cuja fiscalização é feita por amostragem, em razão do número restrito de funcionários em relação à quantidade de processos. Apesar de agilizar a regularização de empreendimentos com menor porte e potencial poluidor, ela exime a realização de estudo detalhado dos impactos ambientais, podendo 0 empreendimento ser instalado de forma inadequada. Sugere-se, para garantir o equilíbrio ecológico e a sadia qualidade de vida, que os órgãos ambientais vistoriem todos empreendimentos, independente da classificação.

Entre os 10 empreendimentos licenciados em caráter corretivo, apenas 2 fazem jus ao benefício da autodenúncia e o restante são processos que tiveram suas licenças indeferidas devido, principalmente, ao não cumprimento das condicionantes estabelecidas pelo órgão ambiental competente, o que acarretou em desempenho ambiental insatisfatório. Entre os ajustes técnicos mais frequentes, destacam-se a utilização de lagoas de decantação e estabilização do efluente, a prática de fertirrigação e o uso de biodigestores anaeróbicos. Ressalta-se que o biodigestor anaeróbico é considerado um Mecanismo de Desenvolvimento Limpo contemplado em políticas de crédito de carbono, permitindo que países em desenvolvimento cerifiquem projetos de redução de emissão de gases de efeito estufa e vendam essas reduções certificadas para países desenvolvidos.

\section{AGRADECIMENTOS}

À Coordenação de Aperfeiçoamento de Pessoal de Nível Superior (CAPES) pelo incentivo financeiro, à Universidade Federal de Lavras (UFLA) pelo apoio às atividades acadêmicas e à Superintendência Regional de Meio Ambiente do Alto São Francisco (SUPRAM - ASF) pela disponibilização de informações relevantes ao trabalho.

\section{REFERÊNCIAS}

BRASIL. Suínos. Brasília: Ministério da Agricultura, Pecuária e Abastecimento, 2016. Disponível em: <http://www.agricultura.gov.br/animal/especies/suinos>. Acesso em: 20 ago. 2016.

CARVALHO, T. M. Diagnóstico dos empreendimentos suinícolas na Bacia do rio Piranga e o índice de qualidade de águas superficiais - IQA. 2014. $160 \mathrm{f}$. Dissertação (Mestrado em Engenharia Ambiental) - Universidade Federal de Ouro Preto. Ouro Preto, 2014.

FAO. Pollution from industrialized livestock production. Livestock Policy Brief 02. Livestock Information Sector Analysis and Policy Branch, Animal Production and Health Division, FAO, Rome; 2005. 
FEAM. Utilização do mecanismo de desenvolvimento limpo: procedimentos para implementação e análise da evolução dos projetos. Belo Horizonte: Fundação Estadual do Meio Ambiente, 2011. 23p.

GARCIA, S. K.; AGUIAR, M. R. Suinocultura em Minas Gerais. Belo Horizonte: Escola de Veterinária - UFMG, 2011. Disponível em: < http://www.asemg.com.br/site/wp-content/uploads/2011/11/SUINOCULTURAMINEIRA-2010-UFMG-IMA-ASEMG-Resumo-novembro2011.pdf>. Acesso em: 20 ago. 2016.

GASPAR, R. M. B. L. Utilização de biodigestores em pequenas e médias propriedades rurais com ênfase na agregação de valor: um estudo de caso na região de Toledo - PR. 2003. 119 f. Dissertação (Mestrado em Engenharia de Produção) - Universidade Federal de Santa Catarina. Florianópolis, 2003.

HERNANDES, J. F. M.; SCHIMDT, V.; MACHADO, J. A. V. Impacto Ambiental da suinocultura em granjas de porte médio a excepcional no Vale do Taquari - RS. Revista de Gestão Social e Ambiental, v.4, n.3, p. 18-31, 2010.

IBGE. Censo Agropecuário 2006. Brasília: IBGE, 2016. Disponível em: <http://www.ibge.gov.br>. Acesso em: 02 ago. 2016.

INSTITUTO FNP. Agrianual 2009: anuário da agricultura brasileira. São Paulo: FNP, 2009. 497p.

KONZEN, E. A.; PEREIRA FILHO, I. A.; BAHIA FILHO, A. F. C.; PEREIRA, F. A Manejo de esterco líquido de suínos e sua utilização na adubação do milho. Sete Lagoas: EMBRAPA-CNPMS, 1998. 31p.

KONZEN, E. A. Dejetos de suínos fermentados em biodigestores e seu impacto como insumo agrícola. In: VII SIMPÓSIO GOIANO DE AVICULTURA E II SIMPÓSIO GOIANO DE SUINOCULTURA, 2005, Goiânia. Anais... Goiânia: Avesui Centrooeste, Seminários técnicos de suinocultura, 2005. p. 56-64.

MERA, C. M. P.; LORENZINI, R.; WOLLMANN, M. R. Percepção com suinocultores de Tapera/RS sobre o uso de dejetos suínos na lavoura e o impacto ambiental. Extensão Rural, Santa Maria, n. 21, p. 77-100, jan./jun. 2011. Disponível em: <https://periodicos.ufsm.br/extensaorural/article/view/5570/3291>. Acesso em: 05 jun. 2017.

MINAS GERAIS. Decreto no 44.844, de 25 de Junho de 2008. Belo Horizonte: Sistema Integrado de Informação Ambiental de Minas Gerais, 2008.

MIRANDA, C. R. Avaliação de estratégias para a sustentabilidade da suinocultura. 2005. 264 f. Tese (Doutorado em Engenharia Ambiental) Universidade Federal de Santa Catarina. Florianópolis, 2005.

NASCIMENTO, R. C; RODRIGUES, G. S. S. C. Impactos Ambientais da suinocultura no município de Uberlândia (MG): Possibilidades de sua mitigação por meio do uso de biodigestores. Revista Caminhos de Geografia. Uberlândia, v. 13, n. 43, p. 230 243, 2012. 
OLIVEIRA, R. A.; FREITAS, W. S.; GALVÃO, J. C. C. et al. Efeito da aplicação de águas residuárias de suinocultura nas características nutricionais do milho. Revista Brasileira de Milho e Sorgo, v.3, n.3, p.357-369, 2004.

SEMAD. Informativo ao suinocultor. Belo Horizonte: Secretaria de Estado de Meio Ambiente e Desenvolvimento Sustentável, 2016. Disponível em: <http://www.meioambiente.mg.gov.br/images/stories/regularizacao_ambiental/cartilh as/informativo-ao-suinocultor-site.pdf >. Acesso em: 10 ago. 2016.

SOUZA, J. A. R.; MOREIRA, D. A.; FERREIRA, P. A. et al. Avaliação de frutos de tomate de mesa produzidos com efluente do tratamento primário da água residuária da suinocultura. Revista Engenharia na Agricultura, Viçosa, v.18, n.3, p. 198-207, 2010.

VIANA, M. B.; BURSZTYN, M. A. A. Regularização ambiental de minerações em Minas Gerais. Revista Escola de Minas, Ouro Preto, v. 63, n. 2, p. 363-369. 